\title{
Identification of a genetic variant at $2 q 12.1$ associated with blood pressure in East-Asians by genome-wide scan including gene-environment interactions
}

Yun Kyoung Kim,2, Youngdoe Kim ${ }^{1}$, Mi Yeong Hwang ${ }^{1}$, Kazuro Shimokawa ${ }^{3}$, Sungho Won ${ }^{4}$, Norihiro Kato ${ }^{3}$, Yasuharu Tabara ${ }^{5}$, Mitsuhiro Yokota ${ }^{6}$, Bok-Ghee Han ${ }^{1}$, Jong Ho Lee ${ }^{2}$ and Bong-Jo Kim ${ }^{1 *}$

\begin{abstract}
Background: Genome-wide association studies have identified many genetic loci associated with blood pressure (BP). Genetic effects on BP can be altered by environmental exposures via multiple biological pathways. Especially, obesity is one of important environmental risk factors that can have considerable effect on BP and it may interact with genetic factors. Given that, we aimed to test whether genetic factors and obesity may jointly influence BP.

Methods: We performed meta-analyses of genome-wide association data for systolic blood pressure (SBP) and diastolic blood pressure (DBP) that included analyses of interaction between single nucleotide polymorphisms (SNPs) and the obesity-related anthropometric measures, body mass index (BMI), height, weight, and waist/hip ratio (WHR) in East-Asians ( $\mathrm{n}=12,030$ ).

Results: We identified that rs13390641 on 2q12.1 demonstrated significant association with SBP when the interaction between SNPs and BMI was considered $\left(P<5 \times 10^{-8}\right)$. The gene located nearest to rs 13390641, TMEM182, encodes transmembrane protein 182. In stratified analyses, the effect of rs 13390641 on BP was much stronger in obese individuals (BMI $\geq 30$ ) than non-obese individuals and the effect of BMI on BP was strongest in individuals with the homozygous A allele of rs13390641.
\end{abstract}

Conclusions: Our analyses that included interactions between SNPs and environmental factors identified a genetic variant associated with BP that was overlooked in standard analyses in which only genetic factors were included. This result also revealed a potential mechanism that integrates genetic factors and obesity related traits in the development of high BP.

Keywords: Blood pressure, Genome-wide scan, Gene-environment interaction, Meta-analysis, Obesity

\section{Background}

High blood pressure (BP) is one of the most common diseases worldwide and is an important risk factor for cardiovascular and renal disease [1,2]. Homeostasis of blood volume, blood vessel resistance and blood thickness are important for regulation of arterial pressure and these are maintained by complex interactions of several

\footnotetext{
* Correspondence: kbj6181@cdc.go.kr

'Division of Structural and Functional Genomics, Center for Genome Science, National Institute of Health, Centers for Disease Control and Prevention, 363-700 Chungcheongbuk-do, Republic of Korea

Full list of author information is available at the end of the article
}

physiological pathways, including hormonal responses, nervous system signaling and intracellular feedback $[3,4]$. Variation in BP also reflects genetic factors with heritability ranging from 30 to $60 \%[5,6]$. Large numbers of genetic variants associated with BP and hypertension have been identified in genome-wide association studies (GWASs) [7-11], but these common variants (minor allele frequency $>5 \%$ ) with relatively small individual effect sizes for BP cannot fully explain the phenotypic variance [7]. To account for much of the heritability of complex traits, greater emphasis is being placed in recent years on gene-environment interaction analyses [12]. Interactions 
involving multiple genes and environmental factors underlying the biological network can potentially elucidate at least part of the missing heritability [13].

High BP develops from a complex interplay of genetic susceptibility factors and environmental factors [14]. A variety of environmental factors have been shown to influence BP, including obesity, physical inactivity, alcohol intake, tobacco use, and diet [1,3]. Obesity, in particular, is a main cause of high BP because it induces sympathoactivation that may raise $\mathrm{BP}[15]$.

To better understand the interactions between genes and environmental risk factors for BP, some candidate gene searches and few GWASs have included geneenvironment interaction terms [16-18]. By using this method in GWAS, incorporation of genetic variations and environmental risk factors may yield additional novel loci that would not appear from analyses based on genetic effect only.

To examine this hypothesis in our study, we performed meta-analyses of GWASs for BP that included interactions between single nucleotide polymorphisms (SNPs) and the obesity-related anthropometric measures of body mass index (BMI), height, weight, and waist-hip ratio (WHR) using 12,030 East-Asians.

\section{Methods}

\section{Study subjects}

For our discovery stage and replication stage 1 study subjects were enlisted from those enrolled in the Korean Genome Epidemiology Study (KoGES) population-based cohort. We selected 7,486 subjects from the Korea Association REsource (KARE) project of KoGES [11] for the discovery stage and 3,703 subjects from the Health Examinee (HEXA) cohort [19] for replication stage 1. KARE project included the initial subjects composed of 10,038 individuals, aged 40 to 69, who were recruited from the Ansung and the Ansan regional cohorts that located in Gyeonggi province, near Seoul, the capital of Korea. Among them, only study subjects who had not been treated for hypertension, thyroid gland disease, osteoporosis, or asthma and who had not taken steroids, oral contraceptives, female sex hormone, or diuretics were included in the baseline for the discovery stage. Subjects of HEXA cohort were randomly selected from 1,200,000 participants of KoGES, aged 40 to 69 , for use as a shared control in genome-wide disease association studies. More detailed explanations of both cohorts were previously described $[11,19]$. All subjects provided written informed consent and this study was approved by ethical committee of the institute (Korea Centers for Disease Control and Prevention Institutional Review Board).

To validate selected SNPs identified in the discovery and replication stage 1 , we performed analyses in replication stage 2 using data collected from a total of 841 subjects enrolled in two independent studies of Japanese populations, the Amagasaki and Ehime studies, described previously [8].

\section{Phenotype determination}

In discovery stage and replication stage 1, BP measurements were conducted using a standard mercury sphygmomanometer after the subjects had been in a sitting position for at least $5 \mathrm{~min}$. In case of replication stage 2, BP was measured by automatic cuff-oscillometric device. The average of two measurements (left and right arm) was taken as the BP. The average of SBPs and DBPs of discovery stage, replication stage 1 and 2 are summarized in Table 1 .

The obesity-related anthropometric measures BMI, height, weight and WHR, were used in this study as environmental risk factors for elevated BP. BMI was defined as weight in $\mathrm{kg}$ divided by the square of height in $\mathrm{m}$. WHR was defined as the ratio of waist $(\mathrm{cm})$ to hip $(\mathrm{cm})$ circumferences. In replication stage 2 , only 3 of 4 anthropometric measures were available, BMI, height, weight except WHR.

\section{Genotyping and quality control}

All of the 10,004 KARE study samples were genotyped using the Affymetrix Genome-Wide Human SNP array 5.0. After quality control, 8,842 subjects and 352,228 SNPs remained for analyses. For in silico replication, 4,302 individuals from the HEXA cohort were genotyped using the Affymetrix Genome-Wide Human SNP array 6.0. After quality control, 3,703 samples and 646,062 SNPs remained. Genotype calling methods and quality control criteria for samples and SNPs of both cohorts have been previously described $[11,19]$.

SNP imputation was conducted using the IMPUTE program [20] based on International HapMap (phase 2, release 22, NCBI build 36 and dbSNP build 126; http:// hapmap.ncbi.nlm.nih.gov/) data from JPT and CHB populations. We used 1,573,409 SNPs for the KARE study and 1,984,393 SNPs for the HEXA cohort after excluding imputed SNPs of unsatisfactory quality for genetic analyses [19].

The results for replication stage 2 were generated from 356 individuals from the Ehime study using the Illumina Human Omni 2.5-8 BeadChip and 485 individuals from the Amagasaki study using the Illumina HumanHap 550 k Quad BeadChip.

\section{Statistical analyses}

Standardized residuals of SBP and DBP adjusted for age and sex by linear regression were used as the phenotypes for analyses in each study. To investigate the effect of interaction between SNPs and the anthropometric measures for BP, we conducted linear regression analyses with interaction terms based on the equation: 
Table 1 Descriptive statistics of study samples

\begin{tabular}{|c|c|c|c|c|c|c|}
\hline \multirow[t]{2}{*}{ Traits } & & \multirow{2}{*}{$\begin{array}{c}\text { Discovery } \\
\text { KARE }(n=7,486)\end{array}$} & \multirow{2}{*}{$\begin{array}{c}\text { Replication } 1 \\
\text { HEXA ( } n=3,703)\end{array}$} & \multicolumn{2}{|c|}{ Replication 2} & \multirow[t]{2}{*}{$* P$} \\
\hline & & & & Ehime $(n=356)$ & Amagasaki $(n=485)$ & \\
\hline Age & & $51.4 \pm 8.77$ & $53.2 \pm 8.33$ & $61.3 \pm 11.2$ & $61.6 \pm 6.97$ & $<0.0001$ \\
\hline \multirow[t]{2}{*}{ Gender } & male (\%) & $3744(50.0 \%)$ & $1651(44.6 \%)$ & $126(35.4 \%)$ & $260(53.6 \%)$ & - \\
\hline & female (\%) & $3742(50.0 \%)$ & $2052(55.4 \%)$ & $230(64.6 \%)$ & 225 (46.3\%) & - \\
\hline \multirow[t]{2}{*}{ Blood pressure } & $\mathrm{SBP}(\mathrm{mmHg})$ & $119.6 \pm 17.4$ & $121.7 \pm 14.4$ & $129.2 \pm 19.7$ & $128.4 \pm 20.8$ & $<0.0001$ \\
\hline & $\overline{\mathrm{DBP}}(\mathrm{mmHg})$ & $79.3 \pm 11.1$ & $77.1 \pm 9.89$ & $74.8 \pm 11.0$ & $77.2 \pm 11.8$ & $<0.0001$ \\
\hline \multirow[t]{4}{*}{ Anthropometric measures } & Height (cm) & $160.5 \pm 8.62$ & $161.5 \pm 8.10$ & $158.0 \pm 8.52$ & $160.1 \pm 7.97$ & $<0.0001$ \\
\hline & Weight (kg) & $63.0 \pm 10.1$ & $62.6 \pm 9.97$ & $56.8 \pm 10.6$ & $59.5 \pm 10.2$ & 0.076 \\
\hline & $\mathrm{BMI}\left(\mathrm{kg} / \mathrm{m}^{2}\right)$ & $24.4 \pm 3.07$ & $24.0 \pm 2.90$ & $22.6 \pm 2.96$ & $23.1 \pm 3.13$ & $<0.0001$ \\
\hline & $\overline{\text { WHR }}$ & $0.88 \pm 0.07$ & $0.86 \pm 0.07$ & - & - & $<0.0001$ \\
\hline
\end{tabular}

$\mathrm{n}$, sample size; SBP, systolic blood pressure; DBP, diastolic blood pressure; BMI, body mass index; WHR, waist-hip ratio.

KARE, Korean Association Resource Project; HEXA, Health Examinee cohort.

Data are shown as mean \pm standard deviation. *P values were analyzed by t-test between the two groups, KARE and HEXA.

$\mathrm{Y}=\beta_{0}+\beta_{1} \times \mathrm{SNP}+\beta_{2} \times$ anthropometric measures (BMI, height, weight, WHR $)+\beta_{3} \times(\mathrm{SNP} \times$ anthropometric measures). $Y$ is the residual of SBP or DBP, $\beta_{0}$ is a constant, $\beta_{1}$ and $\beta_{2}$ are the main effect of a particular SNP and a particular anthropometric measure, respectively, and $\beta_{3}$ is the effect of the interaction term being tested. All of analyses in each stage were conducted using the R program (version 2.15.2; http://www.r-project.org/).

SNPs were selected for replication stage 1 if the SNP's main effect $\mathrm{P}$ value was less than $1 \times 10^{-4}$ in the discovery stage. SNPs that were found to be statistically significant $\left(P_{\mathrm{SNP}}<0.05\right)$ in replication stage 1 were selected for replication stage 2 . To combine association results for selected SNPs in multiple stages (discovery, replication 1 and replication 2), we performed inverse variance weighted metaanalysis for each SNP's main and interactional effects from each stage using the rmeta package of the $\mathrm{R}$ program in which fixed effects were assumed.

After meta-analyses, SNPs with the accepted genomewide significance level $\left(P<5 \times 10^{-8}\right)$, which reflected testing of one million SNPs [21], were considered statistically significant. The more conservative genome-wide significance threshold is $P<3.18 \times 10^{-8}$ based on Bonferroni correction, but no SNP in this study exceeded this threshold. It should be noted that we have selected SNPs which showed the moderate signal $\left(P_{\mathrm{SNP}}<1.0 \times 10^{-4}\right)$ in the discovery stage, expected to be achieved by abundant genetic variants. This stage would require less correction for multiple testing than the final stage targeting at genome-wide significance [22]. From our 3-stage study design, we have discovered a genetic variation that reached genome-wide significance in the final stage.

We also performed stratified analyses to identify the combined effect of BMI and SNP on BP. We tested the association between BMI and BP in each genotype of SNP (ex: GG, GA, AA) and the association between
SNP and BP in each BMI sub-group $(\mathrm{BMI}<18.5$, $18.5 \leq \mathrm{BMI}<25,25 \leq \mathrm{BMI}<30, \mathrm{BMI} \geq 30$ ).

\section{Prediction of TFBS using ENCODE database}

To elucidate the biological meaning of variant, we examined the cluster scores of transcription factor binding sites (TFBS) nearby SNP based on data from all five ENCODE (The Encyclopedia of DNA Elements Consortium) TFBS ChIP-seq production groups via UCSC Genome Browser (http://genome.ucsc.edu/). The UCSC Genome Browser has released a track containing 690 datasets of transcription factor ChIP-seq peaks.

\section{Results}

\section{Descriptive information of study samples}

Table 1 provides the descriptive characteristics of the 12,030 study subjects enlisted for the discovery stage of our analysis from the Korea Association REsource (KARE) project of the Korean Genome Epidemiological Study (KoGES), for replication stage 1 from the Health Examinee cohort (HEXA) of KoGES, and for replication stage 2 from Japanese populations enrolled in the Ehime and Amagasaki studies $[8,11,19]$. The HEXA group had a higher proportion of women (56.6\%) than the KARE group (50.0\%), and the average SBP was higher in the HEXA subjects (121.7 \pm 14.4) than in the KARE subjects (119.6 \pm 17.4$)$. In contrast, the average DBP was higher in the KARE subjects (79.3 \pm $11.1)$ than in the HEXA subjects $(77.1 \pm 9.89)$. All but one (weight) of variables in two groups showed statistically significant differences $(P<0.0001)$. The Japanese populations examined in replication stage 2 tended to be older and to have higher SBP than the HEXA and KARE groups. The correlations between $\mathrm{BP}$ and anthropometric measures are summarized in Additional file 1: Table S1. There were moderate to low correlations between BP and anthropometric measures across the KARE and HEXA subjects 
(Pearson's $r=|0.1 \sim 0.3|)$. But, most of the differences between two independent correlation coefficients were statistically significant (Additional file 1: Table S1).

\section{A genome-wide scan including interaction terms}

We performed genome-wide association analyses on SBP and DBP in the 7,486 KARE subjects with consideration of interaction between approximately 1.6 million SNPs and four obesity-related anthropometric measures using four linear regression models with the following interaction terms: SNP $\times$ BMI, height, weight, or WHR (See Figure 1 for the overall study scheme). Genomic inflation factors $\left(\lambda_{\mathrm{gc}}\right)$ of each SNP's main and interactional effects were calculated for each model. All of the $\lambda_{\mathrm{gc}}$ values were $\leq 1.057$ (Additional file 1: Table S2). The quantilequantile plots for SBP and DBP in each model with interaction terms are presented in Additional file 1: Figure S1.

In discovery stage, we identified several BP associated genetic loci with moderate significance $\left(P_{\mathrm{SNP}}<1.0 \times 10^{-4}\right)$ including some that had not been detected in previous BP-associated GWASs which considered only the SNP's main effects when analyzed (Additional file 1: Table S3). To verify these loci in subsequent stage, we selected the 317 SNPs exceeding $P_{\mathrm{SNP}}<1.0 \times 10^{-4}$ that showed the most significant signals at each locus considering Linkage
Disequilibrium block (LD, $\left.\mathrm{r}^{2}>0.2\right)$ for replication stage 1 with 3,703 HEXA subjects, 146 SNPs associated with SBP only, 150 SNPs associated with DBP only and 21 associated with both SBP and DBP (Additional file 1: Table S3).

In replication stage 1 , we found six SNPs that showed statistical significance $\left(P_{\mathrm{SNP}}<0.05\right)$ in the SNP's main effect with the concordant direction in discovery stage's. These six SNPs were also tested in Japanese populations $(\mathrm{n}=841)$ of replication stage 2 (Additional file 1: Table S4).

In inverse variance meta-analyses combining the results from the three stages for the six SNPs (Additional file 1: Table S4), there was one SNP that reached genome-wide significance $\left(P<5 \times 10^{-8}\right)$. SNP rs13390641, located in the intergenic region on $2 \mathrm{q} 12.1$ near the transmembrane protein 182 gene (TMEM182), was found to be associated with SBP when the interaction between SNP and BMI was considered in the analyses (combined $P_{\mathrm{SNP}}=3.83 \times 10^{-8}$ and $P_{\mathrm{INT}}=5.28 \times 10^{-8}$; Table 2). For rs13390641, there was no evidence for heterogeneity across the three stages (heterogeneity $P=0.47$; Table 2).

\section{Comparison of the effect of rs13390641 and BMI on BP in categorized groups}

We compared the effect estimates for BMI on BP among three genotype classes of rs13390641 by linear regression

\section{Discovery Stage}

GWAS for BP (SBP, DBP) with interaction terms between SNPs and anthropometric measures (BMI, height, weight, WHR) in 7,486 Korean subjects

\ $P_{S N P}<1.0 \times 10^{-4}$

Replication Stage 1

Verification of 317 SNPs selected from discovery stage in 3,703 Korean subjects

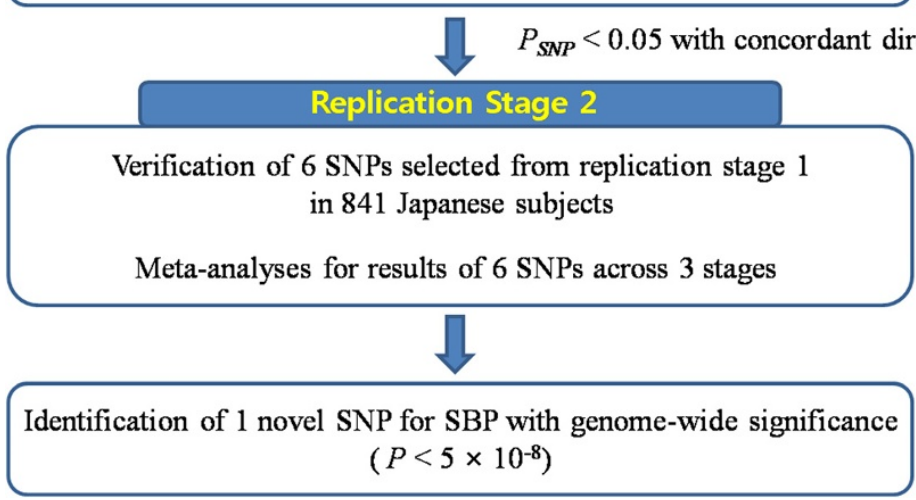

Figure 1 Overall study scheme. We carried out a genome-wide scan for BP-associated (SBP and DBP) SNPs that included interaction terms between SNPs and the anthropometric measures BMI, height, weight, and WHR. After the three-stage analysis (discovery, replication 1, replication 2), we identified a SNP that was strongly associated with SBP by a linear regression model that incorporated interaction between SNPS and BMI. 
Table 2 SNP with a significant effect on BP when considering interaction between SNP and BMI of the subject

\begin{tabular}{|c|c|c|c|c|c|c|c|c|c|c|c|c|c|c|c|}
\hline \multirow{2}{*}{ Trait } & \multirow{2}{*}{ Interaction } & \multirow{2}{*}{$\begin{array}{l}\text { SNP; cytoband; nearby genes; } \\
\text { minor allele/major allele }\end{array}$} & \multirow{2}{*}{$\begin{array}{l}\text { *Type of } \\
\text { effect }\end{array}$} & \multicolumn{3}{|c|}{ Discovery $(n=7,486)$} & \multicolumn{3}{|c|}{ Replication $1(n=3,703)$} & \multicolumn{3}{|c|}{ Replication $2(n=841)$} & \multicolumn{3}{|c|}{ Combined $(n=12,030)$} \\
\hline & & & & MAF & Beta (se) & $P$ & MAF & Beta (se) & $P$ & MAF & Beta (se) & $P$ & Beta (se) & $P$ & $P_{\text {het }}(Q)$ \\
\hline \multirow[b]{2}{*}{ SBP } & \multirow[b]{2}{*}{ BMI } & \multirow{2}{*}{$\begin{array}{l}\text { \#rs13390641; 2q12.1; } \\
\text { TMEM182; A/G }\end{array}$} & SNP main & \multirow[b]{2}{*}{0.11} & $-13.9(3.35)$ & $3.51 \times 10^{-5}$ & \multirow[b]{2}{*}{0.10} & $-11.6(4.35)$ & $7.73 \times 10^{-3}$ & \multirow[b]{2}{*}{0.10} & $-32.1(12.5)$ & $1.01 \times 10^{-2}$ & $-14.4(2.62)$ & $3.83 \times 10^{-8}$ & $0.47(2.52)$ \\
\hline & & & Interaction & & $0.56(0.14)$ & $3.80 \times 10^{-5}$ & & $0.47(0.18)$ & $9.39 \times 10^{-3}$ & & $1.35(0.54)$ & $1.21 \times 10^{-2}$ & $0.59(0.11)$ & $5.28 \times 10^{-8}$ & $0.48(2.49)$ \\
\hline
\end{tabular}

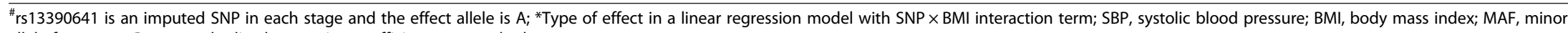
allele frequency; Beta, standardized regression coefficient; se, standard error.

A test of heterogeneity $\left(P_{\text {het }}\right)$ was conducted; $Q$, Cochrane's $Q$ value based on chi-squared statistics.

Age and sex were covariates in this analysis. 
Table 3 Effect of BMI on BP by rs13390641 genotype classes

\begin{tabular}{lcccc}
\hline Trait & Genotype & $\mathbf{n}$ & Beta (se) & $\boldsymbol{P}$ \\
\hline SBP & GG & 8980 & $0.92(0.05)$ & $4.62 \times 10^{-66}$ \\
\hline & GA & 2051 & $1.32(0.11)$ & $5.76 \times 10^{-32}$ \\
\hline DBP & AA & 135 & $1.58(0.47)$ & $9.68 \times 10^{-4}$ \\
\hline & GG & 8980 & $0.75(0.04)$ & $7.81 \times 10^{-96}$ \\
\hline & GA & 2051 & $0.99(0.07)$ & $2.02 \times 10^{-39}$ \\
\hline
\end{tabular}

SBP, systolic blood pressure; DBP, diastolic blood pressure; $n$, sample size of each subgroup; Beta, standardized regression coefficient; se, standard error. The association analyses between $\mathrm{BP}$ and $\mathrm{BMI}$ in each group were performed using linear regression adjusted by age and sex.

analyses of the KARE and HEXA subjects $(n=11,189)$. The strongest effect of BMI was for SBP in subjects carrying the homozygous A allele of rs13390641 (Beta = $1.58, P=9.68 \times 10^{-4}$ ). In the case of DBP, the effect of BMI was also highest in subjects carrying the homozygous A allele (Beta $=1.35, P=3.26 \times 10^{-5}$; Table 3 and Figure 2).

We also calculated effect estimates for rs13390641 on $\mathrm{BP}$ in four BMI sub-groups. In the highest BMI sub-group $(B M I \geq 30)$, rs13390641 showed a strong increasing effect on SBP $\left(\right.$ Beta $\left.=5.35, P=3.22 \times 10^{-3}\right)$. For DBP, the effect of rs13390641 also increased significantly in the highest BMI sub-group (Beta $=3.50, P=3.24 \times 10^{-3}$; Table 4 and Figure 2). It is enough to say that the subjects in the highest BMI sub-group with carrying A allele may have a higher risk of increasing BP significantly.

\section{Discussion}

Few studies have examined the potential interaction between SNPs and environmental risk factors that modulate complex traits on a genome-wide scale. The major strength of our study was that it was able to detect a previously overlooked BP-associated genetic factor, rs13390641, with genome-wide significance $\left(P<5 \times 10^{-8}\right)$ because our analyses considered interaction between SNPs and obesity related anthropometric measures.

The estimated effect of BMI on BP was larger in individuals carrying two copies of the A allele of rs13390641 than in those carrying two copies of the G allele (Table 3) and the effect of rs13390641 on BP was larger in obese individuals (BMI $\geq 30)$ than in the other subjects (Table 4). These stratified analyses strongly suggest that the joint effect of rs13390641 and obesity (BMI) on risk of developing BP identified that the effect in the obese individuals carrying risk (A) alleles (GA or AA genotype) was much higher than that in obese individuals carrying non-risk $(\mathrm{G})$ alleles.

The rs13390641 SNP is located intergenic region, $602 \mathrm{~kb}$ downstream of the gene that encodes transmembrane protein 182, which is composed of four putative membranespanning regions [23]. There were low correlation between variants in TMEM182 and rs13390641 (Pearson's correlation coefficient, $r \approx 0.10$ ) (Additional file 1 : Figure $S 2$ ). We also examined LD block between variants in TMEM182 and rs13390641 using Haploview software based on HapMap release 22, CHB + JPT panel. These variants located in a same locus, $2 \mathrm{q} 12.1$, but were not in a $\mathrm{LD}$ (Additional file 1: Figure S3). However, interestingly, there were several transcription factor binding sites located between TMEM182 and rs13390641. Of them, binding sites for RAD21, CTCF and STAT1 showed the highest cluster scores that were 767,500 and 769, respectively (Visualization in the UCSC Genome Browser, http:// genome.ucsc.edu/). Especially, STAT1 plays a part in the process of blood circulation (referring to the Gene (a) The effect of BMI on BP by rs13390641

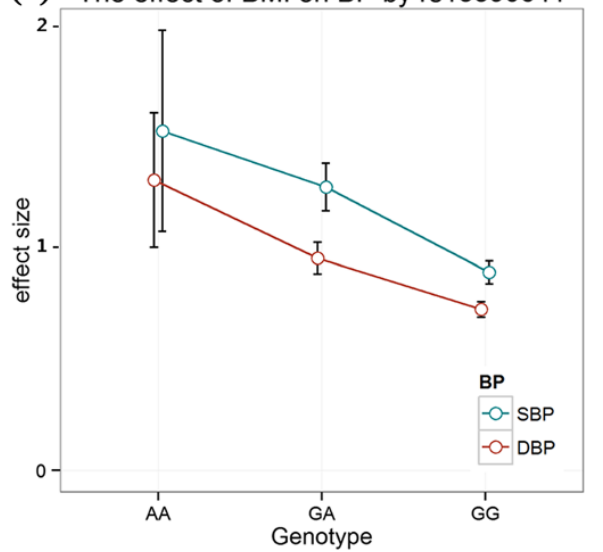

(b) The effect of rs13390641 on BP by BMI

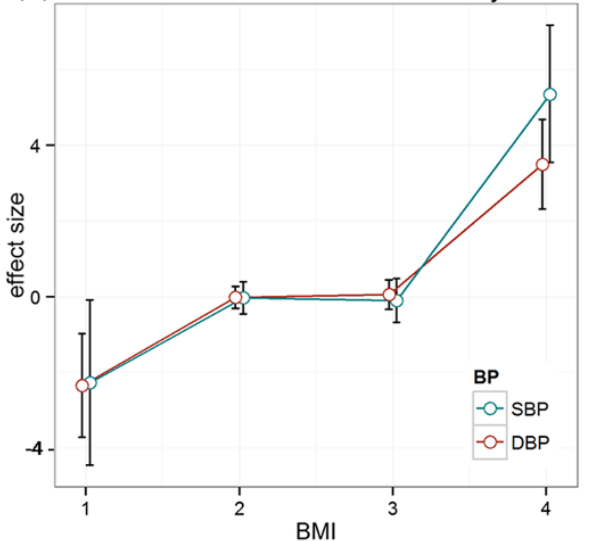

Figure 2 Effect size of BMI and rs13390641 on BP. (a) Effect of BMI on SBP and DBP in the three rs13390641 genotypes. (b) Effect of rs13390641 on SBP and DBP in the four BMl groups. Group 1: BMl < 18.5, Group 2: $18.5 \leq \mathrm{BMl}<25$, Group 3: $25 \leq \mathrm{BMl}<30$, and Group 4: BMI $\geq 30$. Data are the mean \pm standard deviation. 
Table 4 Effect of rs13390641 on BP by BMI sub-groups

\begin{tabular}{lcccc}
\hline Trait & BMl sub-group & $\mathbf{n}$ & Beta (se) & $\boldsymbol{P}$ \\
\hline SBP & $\mathrm{BMI}<18.5$ & 212 & $-2.26(2.18)$ & 0.2993 \\
\hline & $18.5 \leq \mathrm{BMl}<25$ & 6700 & $-0.02(0.43)$ & 0.9540 \\
\hline $25 \leq \mathrm{BMl}<30$ & 3850 & $-0.10(0.58)$ & 0.8690 \\
\hline DBP & $\mathrm{BMl}<18.5$ & 212 & $-2.34(1.37)$ & 0.0884 \\
\hline & $18.5 \leq \mathrm{BMl}<25$ & 6700 & $-0.01(0.29)$ & 0.9600 \\
\hline & $25 \leq \mathrm{BMl}<30$ & 3850 & $0.06(0.39)$ & 0.8720 \\
\hline $30 \leq \mathrm{BMl}$ & 427 & $3.50(1.18)$ & 0.0032
\end{tabular}

SBP, systolic blood pressure; DBP, diastolic blood pressure; BMI, body mass index; $n$, sample size of each subgroup; Beta, standardized regression coefficient; se, standard error; The association analyses between BP and rs 13390641 in each group were performed using linear regression adjusted by age and sex.

Ontology). It may affect to regulate the expression of TMEM182 and suggests a possible modulation of BP level.

No phenotypes with a direct functional connection to TMEM182 have been reported, but its expression in adipocytes and its potential role in glaucoma have been explored [23,24]. Elevated levels of the proinflammatory cytokine TNF- $\alpha$ are associated with obesity $[25,26]$. TNF- $\alpha$ also regulates the expression of TMEM182 in white adipose tissue [23]. Taken together, these results suggest that expression of TMEM182 may be integral to the adipocyte phenotype mediated by the TNF- $\alpha$ pathway, and that TMEM182 may act on BP.

$\mathrm{Up}$ to date, some studies have discovered genetic variants associated BP via GWAS using KARE subjects [27-30]. These studies have identified 8 genes, PARK2, OPA1, ATP2B1, CSK, ARSG, CSMD1, CYP17A1 and PLEKHA7 that located SNPs associated BP or hypertension. We have tested genetic effects of 22 SNPs on 8 genes for SBP considered interaction between SNPs and BMI. However, none of them represented the statistical significance in this interaction model (Additional file 1: Table S5). It is due to method of analyses that previous studies conducted standard analyses which considered only genetic effects, on the other hand, our analyses considered not only genetic effects but also interactional effects. According to the different method, it is natural that the result came out differently. So, these previously known SNPs associated $\mathrm{BP}$ based on KARE subjects were not to be considered as candidates for BP in our analyses.

Although we uncovered only a single locus with significant genome-wide association with BP, possibly because of genetic diversity and differences in environmental effects between populations, this is the first study to examine genome-wide associations of $\mathrm{BP}$ with interacting genetic and environmental risk factors in East-Asian populations. Incorporating gene-environment interactions may be critical for discovering genetic determinants of complex traits such as BP, as these interactions may better explain the variance of complex traits than direct effects of individual genes.

\section{Conclusions}

In conclusion, this genome-wide screen for BP-associated genes, which considered interaction between SNPs and obesity-related anthropometric measures, identified a genetic variant in East-Asian populations near TMEM182 that may influence BP. This study suggests a useful strategy for discovering new genetic contributors of complex traits, which may work together with environmental factors to cause human diseases.

\section{Additional file}

Additional file 1: Figure S1. The quantile - quantile plots for SBP and DBP in each model with interaction terms in discovery stage. Figure S2. Pearson's correlation coefficient ( $r$ ) between rs13390641 and 206 SNPs located from TMEM182 to rs13390641 (Chr 2:102744010 - 103402865). Figure S3. The linkage disequilibrium (LD) block between rs13390641 and SNPS on TMEM182. Table S1. Correlation of BP and anthropometric measures. Table S2. Genomic inflation factors of analyses in each model with interaction terms in the discovery stage. Table S3. Results of genome-wide association analyses in discovery stage. Table S4. Results of combined meta-analyses for selected 6 SNPs. Table S5. Results of association analyses for SBP considered interaction between BMI and known SNPs that were revealed by earlier experiences within the KARE project.

\section{Competing interests}

The authors declare that they have no competing interests.

\section{Authors' contributions}

YKK provided the design of the project and performed data analysis, writing and editing manuscript. YK and MYH participated in data analysis, KS carried out data analysis in replication stage 2. SW reviewed data, and NK, YT and MY provided the data of Japanese population. B-GH, JHL and B-JK participated in general discussion, reviewed data and editing manuscript. All authors read and approved the final manuscript.

\section{Acknowledgements}

This work was supported by an intramural grant from the Korea National Institute of Health (2012-N73002-00) and a grant from the Korea Centers for Disease Control and Prevention (4845-301, 4851-302, 4851-307).

\section{Author details}

${ }^{1}$ Division of Structural and Functional Genomics, Center for Genome Science, National Institute of Health, Centers for Disease Control and Prevention, 363-700 Chungcheongbuk-do, Republic of Korea. 'Department of Food and Nutrition, College of Human Ecology, Yonsei University, Seoul, Republic of Korea. ${ }^{3}$ Department of Gene Diagnostics and Therapeutics Research Institute, National Center for Global Health and Medicine, Tokyo, Japan. ${ }^{4}$ Department of Applied Statistics, Chung-Ang University, Seoul, Republic of Korea. ${ }^{5}$ Center for Genomic Medicine, Kyoto University Graduate School of Medicine, Kyoto, Japan. ${ }^{6}$ Department of Genome Science, Aichi-Gakuin University, School of Dentistry, Nagoya, Japan.

Received: 14 January 2014 Accepted: 2 June 2014

Published: 5 June 2014 


\section{References}

1. Whitworth JA: 2003 World Health Organization (WHO)/International Society of Hypertension (ISH) statement on management of hypertension. J Hypertens 2003, 21(11):1983-1992.

2. Wadei HM, Textor SC: The role of the kidney in regulating arterial blood pressure. Nat Rev Nephrol 2012, 8(10):602-609.

3. Padmanabhan S, Newton-Cheh C, Dominiczak AF: Genetic basis of blood pressure and hypertension. Trends Genet 2012, 28(8):397-408.

4. Staessen JA, Wang J, Bianchi G, Birkenhager WH: Essential hypertension. Lancet 2003, 361(9369):1629-1641.

5. Hottenga JJ, Boomsma DI, Kupper N, Posthuma D, Snieder H, Willemsen G, de Geus EJ: Heritability and stability of resting blood pressure. Twin Res Hum Genet 2005, 8(5):499-508.

6. Kupper N, Willemsen G, Riese H, Posthuma D, Boomsma DI, de Geus EJ: Heritability of daytime ambulatory blood pressure in an extended twin design. Hypertension 2005, 45(1):80-85.

7. Ehret GB, Munroe PB, Rice KM, Bochud M, Johnson AD, Chasman DI, Smith $A V$, Tobin MD, Verwoert GC, Hwang SJ, Pihur V, Vollenweider P, O'Reilly PF, Amin N, Bragg-Gresham JL, Teumer A, Glazer NL, Launer L, Zhao JH, Aulchenko Y, Heath S, Söber S, Parsa A, Luan J, Arora P, Dehghan A, Zhang F, Lucas G, Hicks AA, Jackson AU: Genetic variants in novel pathways influence blood pressure and cardiovascular disease risk. Nature 2011, 478(7367):103-109.

8. Kato N, Takeuchi F, Tabara Y, Kelly TN, Go MJ, Sim X, Tay WT, Chen CH, Zhang Y, Yamamoto K, Katsuya T, Yokota M, Kim YJ, Ong RT, Nabika T, Gu D, Chang LC, Kokubo Y, Huang W, Ohnaka K, Yamori Y, Nakashima E, Jaquish CE, Lee JY, Seielstad M, Isono M, Hixson JE, Chen YT, Miki T, Zhou X: Meta-analysis of genome-wide association studies identifies common variants associated with blood pressure variation in east Asians. Nat Genet 2011, 43(6):531-538.

9. Adeyemo A, Gerry N, Chen G, Herbert A, Doumatey A, Huang H, Zhou J, Lashley K, Chen Y, Christman M, Rotimi C: A genome-wide association study of hypertension and blood pressure in African Americans. PLoS Genet 2009, 5(7):e1000564

10. Newton-Cheh C, Johnson T, Gateva V, Tobin MD, Bochud M, Coin L, Najjar SS, Zhao JH, Heath SC, Eyheramendy S, Papadakis K, Voight BF, Scott L, Zhang F, Farrall M, Tanaka T, Wallace C, Chambers JC, Khaw KT, Nilsson P, van der Harst P, Polidoro S, Grobbee DE, Onland-Moret NC, Bots ML, Wain LV, Elliott KS, Teumer A, Luan J, Lucas G: Genome-wide association study identifies eight loci associated with blood pressure. Nat Genet 2009, 41(6):666-676.

11. Cho YS, Go MJ, Kim YJ, Heo JY, Oh JH, Ban HJ, Yoon D, Lee MH, Kim DJ, Park M, Cha SH, Kim JW, Han BG, Min H, Ahn Y, Park MS, Han HR, Jang HY, Cho EY, Lee JE, Cho NH, Shin C, Park T, Park JW, Lee JK, Cardon L, Clarke G, McCarthy MI, Lee JY, Lee JK: A large-scale genome-wide association study of Asian populations uncovers genetic factors influencing eight quantitative traits. Nat Genet 2009, 41(5):527-534.

12. Manolio TA, Collins FS, Cox NJ, Goldstein DB, Hindorff LA, Hunter DJ, McCarthy Ml, Ramos EM, Cardon LR, Chakravarti A, Cho JH, Guttmacher AE, Kong A, Kruglyak L, Mardis E, Rotimi CN, Slatkin M, Valle D, Whittemore AS, Boehnke M, Clark AG, Eichler EE, Gibson G, Haines JL, Mackay TF, McCarroll SA, Visscher PM: Finding the missing heritability of complex diseases. Nature 2009, 461(7265):747-753.

13. Eichler EE, Flint J, Gibson G, Kong A, Leal SM, Moore JH, Nadeau JH: Missing heritability and strategies for finding the underlying causes of complex disease. Nat Rev Genet 2010, 11(6):446-450.

14. Pausova Z, Tremblay J, Hamet P: Gene-environment interactions in hypertension. Curr Hypertens Rep 1999, 1(1):42-50.

15. Pausova Z: From big fat cells to high blood pressure: a pathway to obesity-associated hypertension. Curr Opin Nephrol Hypertens 2006, 15(2):173-178.

16. Taylor JY, Sun YV, Hunt SC, Kardia SL: Gene-environment interaction for hypertension among African American women across generations. Biol Res Nurs 2010, 12(2):149-155.

17. Tsuchihashi-Makaya M, Serizawa M, Yanai K, Katsuya T, Takeuchi F, Fujioka A, Yamori Y, Ogihara T, Kato N: Gene-environmental interaction regarding alcohol-metabolizing enzymes in the Japanese general population. Hypertens Res 2009, 32(3):207-213.

18. Sabatti C, Service SK, Hartikainen AL, Pouta A, Ripatti S, Brodsky J, Jones CG, Zaitlen NA, Varilo T, Kaakinen M, Sovio U, Ruokonen A, Laitinen J, Jakkula E, Coin L, Hoggart C, Collins A, Turunen H, Gabriel S, Elliot P, McCarthy MI,
Daly MJ, Järvelin MR, Freimer NB, Peltonen L: Genome-wide association analysis of metabolic traits in a birth cohort from a founder population. Nat Genet 2009, 41(1):35-46.

19. Kim YJ, Go MJ, Hu C, Hong CB, Kim YK, Lee JY, Hwang JY, Oh JH, Kim DJ, Kim NH, Kim S, Hong EJ, Kim JH, Min H, Kim Y, Zhang R, Jia W, Okada Y, Takahashi A, Kubo M, Tanaka T, Kamatani N, Matsuda K, Park T, Oh B, Kimm K, Kang D, Shin C, Cho NH, MAGIC consortium: Large-scale genome-wide association studies in East Asians identify new genetic loci influencing metabolic traits. Nat Genet 2011, 43(10):990-995.

20. Marchini J, Howie B, Myers S, McVean G, Donnelly P: A new multipoint method for genome-wide association studies by imputation of genotypes. Nat Genet 2007, 39(7):906-913.

21. Moskvina V, Schmidt KM: On multiple-testing correction in genome-wide association studies. Genet Epidemiol 2008, 32(6):567-573.

22. Pe'er I, Yelensky R, Altshuler D, Daly MJ: Estimation of the multiple testing burden for genomewide association studies of nearly all common variants. Genet Epidemiol 2008, 32(4):381-385.

23. Wu Y, Smas CM: Expression and regulation of transcript for the novel transmembrane protein Tmem182 in the adipocyte and muscle lineage. BMC Res Notes 2008, 1:85.

24. Shi D, Funayama T, Mashima Y, Takano Y, Shimizu A, Yamamoto K, Mengkegale M, Miyazawa A, Yasuda N, Fukuchi T, Abe H, Ideta H, Nishida K, Nakazawa T, Richards JE, Fuse N: Association of HK2 and NCK2 with normal tension glaucoma in the Japanese population. PLoS One 2013, 8(1):e54115.

25. Ruan H, Hacohen N, Golub TR, Van Parijs L, Lodish HF: Tumor necrosis factor-alpha suppresses adipocyte-specific genes and activates expression of preadipocyte genes in 3 T3-L1 adipocytes: nuclear factor-kappaB activation by TNF-alpha is obligatory. Diabetes 2002, 51(5):1319-1336.

26. Wellen KE, Uysal KT, Wiesbrock S, Yang Q, Chen H, Hotamisligil GS: Interaction of tumor necrosis factor-alpha- and thiazolidinedione-regulated pathways in obesity. Endocrinology 2004, 145(5):2214-2220.

27. Jin HS, Hong KW, Kim BY, Kim J, Yoo YH, Oh B, Jeong SY: Replicated association between genetic variation in the PARK2 gene and blood pressure. Clin Chim Acta 2011, 412(17-18):1673-1677.

28. Jin HS, Sober S, Hong KW, Org E, Kim BY, Laan M, Oh B, Jeong SY: Age-dependent association of the polymorphisms in the mitochondria-shaping gene, OPA1, with blood pressure and hypertension in Korean population. Am J Hypertens 2011, 24(10):1127-1135.

29. Hong KW, Go MJ, Jin HS, Lim JE, Lee JY, Han BG, Hwang SY, Lee SH, Park HK, Cho YS, Oh B: Genetic variations in ATP2B1, CSK, ARSG and CSMD1 loci are related to blood pressure and/or hypertension in two Korean cohorts. J Hum Hypertens 2010, 24(6):367-372.

30. Hong KW, Jin HS, Lim JE, Kim S, Go MJ, Oh B: Recapitulation of two genomewide association studies on blood pressure and essential hypertension in the Korean population. J Hum Genet 2010, 55(6):336-341

doi:10.1186/1471-2350-15-65

Cite this article as: Kim et al: Identification of a genetic variant at 2q12.1 associated with blood pressure in East-Asians by genome-wide scan including gene-environment interactions. BMC Medical Genetics 2014 15:65.

\section{Submit your next manuscript to BioMed Central and take full advantage of:}

- Convenient online submission

- Thorough peer review

- No space constraints or color figure charges

- Immediate publication on acceptance

- Inclusion in PubMed, CAS, Scopus and Google Scholar

- Research which is freely available for redistribution 